\title{
Treatment of Post-Traumatic Stress Disorder in Children Using Cognitive Behavioural Writing Therapy
}

\author{
Saskia Van der Oord, ${ }^{1,2 *}$ S. Lucassen, ${ }^{2,3}$ \\ A. A. P. Van Emmerik ${ }^{1}$ and P. M. G. Emmelkamp ${ }^{\mathbf{1}}$ \\ ${ }^{1}$ Department of Clinical Psychology, University of Amsterdam, Amsterdam, \\ The Netherlands \\ ${ }^{2}$ Lucertis, Outpatient Children's Mental Health Clinic, Zaandam, The Neth- \\ erlands \\ ${ }^{3}$ UVA-Virenze, Outpatient Children's Mental Health Clinic, Amsterdam, The \\ Netherlands
}

Objectives: This study evaluated the effectiveness of Cognitive Behavioral Writing Therapy (CBWT) in 23 children (age 8-18 years) in the Netherlands, who experienced a range of single and recurrent traumatic experiences. CBWT uses exposure, cognitive restructuring and social sharing. Methods: At pre-test, post-test and follow-up, post-traumatic stress disorder (PTSD) symptoms, depressive symptoms, trauma-related cognitions and general behavioural problems were assessed. Results: At post-test there was a significant reduction of all symptoms, and this effect was maintained at 6 months follow-up. The mean amount of treatment sessions needed was 5.5. Conclusions: This study shows that short-term CBWT is a potentially effective intervention for clinically referred traumatized children. There is now a clear need of establishing the effectiveness of CBWT in a randomized, controlled trial. Practice implication: This first study indicates CBWT is a promising treatment, which can easily be used in clinical practice. Copyright $@ 2009$ John Wiley \& Sons, Ltd.

Key practitioner massage:

- CWBT can easily be implemented in clinical practice.

- CWBT is suitable for a clinically representative group of children and adolescents with PTSD, who have experienced a wide range of single and recurrent traumatic experiences.

- CWBT is a short-term potentially effective treatment.

Keywords: PTSD, Child, Adolescent, CBT, Writing, Treatment

\section{INTRODUCTION}

In contrast to post-traumatic stress in adults, where a steady increase in research has taken place since 1980, relatively few studies have investigated

* Correspondence to: Saskia van der Oord, Department of Clinical Psychology, University of Amsterdam, Roetersstraat 15, 1018 WB Amsterdam, The Netherlands.

Email: s.vanderoord@uva.nl the prevalence of post-traumatic stress disorder (PTSD), characteristics of stressors and treatment of PTSD in children and adolescents. The studies that were conducted, however, considerably broadened the list of potentially traumatic situations in childhood and adolescence. For example, a parent being sent to prison or mental hospital, suicide of a parent or loved one, being exposed to peer violence and learning of a traumatic event occurring to a parent or loved one have been identified 
as potential causes of PTSD in childhood (e.g. Cuffe et al., 1998; Finkelor, Turner, \& Ormrod, 2006; Giaconia et al., 1995) in addition to wellrecognized traumatic events, such as sexual abuse or traffic accidents. PTSD in childhood is associated with a variety of internalizing and externalizing problems, and additional disorders next to PTSD (Bolton, O'Ryan, Udwin, Boyle, \& Yule, 2000). If children with PTSD are not treated adequately, these symptoms may persist into adulthood and lead to chronic PTSD (Yule et al., 2000). Hence, there is a clear need of evidence-based treatments for childhood PTSD, which can be easily implemented in regular clinical practice.

The development of empirically supported treatments for PTSD in childhood has lagged far behind that for PTSD in adults (Bisson et al., 2007; Silverman et al., 2008). Fewer studies have been published on the effectiveness of cognitive behavioural treatment for children with PTSD (e.g. Cohen, Deblinger, Mannorino, \& Steer, 2004; Cohen, Mannarino, \& Staron, 2006; Deblinger, Lippman, \& Steer, 1996; King et al., 2000; Smith et al., 2007; Stein et al., 2003; for review see Silverman et al., 2008). These studies show that cognitive behavioural treatment is more effective than a waitlist control condition, community treatment, supportive therapy or child-centred therapy on short- and long-term outcome measures. However, the cognitive behavioural treatments described in these studies differ considerably in content and length. For example, some studies include anxiety management procedures in their cognitive behavioural treatments (e.g. Cohen et al., 2004; Deblinger et al., 1996; King et al., 2000), while others make more use of cognitive techniques instead (Smith et al., 2007).

Also, existing treatment studies differ in the type of trauma that led to the PTSD. Most treatment studies included children displaying traumatic symptoms after being exposed to one specific type of trauma, such as sexual assault (e.g. Cohen et al., 2004; Deblinger et al., 1996; King et al., 2000; for review see Silverman et al., 2008), violence (Stein et al., 2003), or the death of a parent or loved one (Cohen et al., 2006).

No treatment studies in regular clinical settings exist that included children experiencing PTSD due to a wider range of traumatic events (such as child abuse, domestic violence, accidents or sudden traumatic loss of a loved one) and included both single traumatic events (Smith et al., 2007) and repeated traumatic experiences, in a wide age range in children from 8 to 18 years old. Therefore, this is the first study that evaluates computerized cognitive behavioural writing treatment in a clinical sample of children with PTSD after a range of traumatic experiences.

In conventional cognitive behavioural treatment, two elements are considered to be crucial. First, through imaginal exposure habituation to aversive stimuli should occur, and second, through cognitive restructuring trauma-related dysfunctional cognitions should be replaced by more helpful beliefs (Ehlers \& Clark, 2000). In the adult literature, structured writing is emerging as an alternative set of procedures for imaginal exposure and cognitive restructuring (e.g. Lange et al., 2003; Van Emmerik, Kamphuis, \& Emmelkamp, 2008). Written exposure is thought to be effective through similar mechanisms as conventional cognitive behavioural interventions in which the patient is exposed to aversive stimuli either imaginally or in vivo (Sloan, Marx, \& Epstein, 2005; Sloan, Marx, Epstein \& Lexington, 2007). An additional advantage of cognitive behavioural writing assignments is that an actual essay is produced, which can be shared with important others such as partners or parents. This element is called social sharing (Lange et al., 2003) and may be especially important, since the absence of social support following trauma is an important predictor of the development of PTSD (Brewin, Andrews, \& Valentine, 2000; Ozer \& Weinstein, 2004). In adults, cognitive behavioural writing therapy for PTSD is equally effective to face-to-face cognitive behavioural treatment (Van Emmerik et al., 2008).

Cognitive behaviour therapy for PTSD solely using writing procedures has not yet been investigated in children. Some treatment manuals include optional writing procedures (next to drawing, or other expressive methods) to facilitate exposure (e.g. Trauma Focussed Cognitive Behavior Therapy [TF-CBT]; Cohen, Mannarino, \& Deblinger, 2006), but the current modality, CBT solely through writing in the session on the computer, has not been evaluated yet.

A treatment that explicitly only uses the trauma narrative is Narrative Exposure Treatment (NET; Neuner, Schauer, Klaschik, Karunakara, \& Elbert, 2004). Similar to conventional exposure therapy, NET aims to reduce PTSD symptoms by confronting the patient with the memories of the traumatic event (Onyut et al., 2005). The focus of NET is to integrate the typically fragmented, gap-filled reports of traumatic experiences into a coherent narrative and to bring about the habituation of emotional responses to reminders of the traumatic event (Bichescu, Neuner, Schauer, \& Elbert, 
2007). Although NET puts emotional memories into words and contrasts them with the emotional experience during the recall (Bichescu et al., 2007), other therapeutic techniques, such as cognitive restructuring and social sharing, are not explicitly included in NET.

In two controlled studies with adults NET is effective in the reduction of PTSD symptoms (Bichescu et al., 2007; Neuner et al., 2004). Also, an adapted child treatment is available (KidNET). Case reports show that in children exposed to war trauma, KidNET produced a significant reduction of PTSD symptoms and depression (Neuner et al., 2008; Onyut et al., 2005; Schauer et al., 2004).

The current CBWT is based on the cognitive behavioural writing treatment of Lange et al. (INTERAPY; 2003), which was developed for treatment through the internet and has exposure, cognitive restructuring and social sharing as its most important elements. The treatment was adapted for use with children. While adult patients in cognitive behavioural writing therapy typically complete their writing assignments at home (e.g. Van Emmerik et al., 2008; Lange et al., 2003), children in the present therapy completed their assignments on a computer during the treatment sessions, aided by the therapist. In TF-CBT (e.g. Cohen et al., 2006), next to other treatment modules such as relaxation, one treatment module focuses on constructing a trauma narrative. This is often done through writing and is sometimes computer aided, but also sometimes through other imaginal procedures, such as drawing or other expressive methods. The trauma narrative is also shared with a parent or other adult. CBWT differs from TF-CBT in the way that it always uses a written narrative of the traumatic experience, always is computer aided, and that during the whole course of the treatment a storyline of the traumatic experience is constructed, in which all elements of treatment (exposure, cognitive restructuring, social sharing) are integrated.

To our knowledge, this is the first study using computed-aided CBWT in children and adolescents with PTSD after a range of single and recurrent traumas in an outpatient community mental health setting in a wide age-range of children and adolescents. The study assesses the feasibility and initial efficacy of this treatment, on symptoms of PTSD, depression and parent-rated behavioural and emotional problems. Since cognitive restructuring is an element of treatment, before and after treatment trauma-related cognitions were assessed. Further, treatment satisfaction was evaluated. CBWT was expected to reduce symptoms of PTSD, dysfunc- tional trauma-related cognitions, symptoms of depression, and parent-reported behavioural and emotional problems.

\section{METHOD}

\section{Participants}

Participants were children in the age from 8 through 18 years, referred to an outpatient community mental health clinic in the Netherlands with trauma-related symptoms. After the parents had given informed consent, children and parents were interviewed with the ADIS-Parent version and ADIS-Child version (see Measures) to establish the presence of PTSD and comorbid disorders. Children older than 12 years also gave their informed consent for the study. The Ethics Committee of the University of Amsterdam approved the protocol and informed consent procedure of the study.

\section{Inclusion/Exclusion Criteria}

Similar to other studies on treatment of childhood PTSD (e.g. Cohen et al., 2004) inclusion criteria were: (1) a diagnosis of PTSD and if not meeting criteria for full blown PTSD, (a) having at least five PTSD symptoms (as measured by the ADIS$\mathrm{C}$ and ADIS-P) due to a traumatic experience, reported by either parent or child, (b) having at least one symptom in each of the three PTSD clusters, and (c) experiencing clinically significant impairment. Although children who fulfilled the above criteria but did not meet the Diagnostic and Statistical Manual of Mental Disorders, 4th edition (DSM-IV-TR) diagnosis of PTSD were included, the majority of our sample (87\% of the children) had a diagnosis of full-blown PTSD. Further, children were excluded if they had an estimated IQ of 80 or lower, if there was an ongoing trauma-related threat, if the home situation was so unstable that other interventions were required, or if other psychiatric problems were present that needed urgent treatment. For every child, the inclusion and exclusion criteria were discussed in a multidisciplinary team of psychologists, social workers and a child psychiatrist.

\section{MEASURES}

\section{Selection Measure}

The Anxiety Disorder Interview Schedule (ADIS; Silberman \& Albano, 1996; Dutch translation: 
Siebelink \& Treffers, 2001) interviews were carried out by a trained research assistant. The ADIS is a semistructured interview that assesses DSM-IV symptoms of PTSD and other disorders. Since this study was embedded in regular clinical practice, only common anxiety disorders in children (i.e. separation anxiety disorder, generalized anxiety disorder, social phobia, specific phobia, PTSD) were assessed.

\section{Outcome Measures}

\section{General Behaviour Problems}

At both pre- and post-test, the primary caretaker reported on the behavioural and emotional problems of the child using the Child Behavior Check List (CBCL; Achenbach, 1991). The CBCL is a 113item parent report instrument, which measures a variety of emotional and behavioural difficulties of the child, and is rated on a three-point scale. It includes three broad band scales (Internalizing Problems, Externalizing Problems, and Total Behavioural Problems) and eight narrow band scales. For this study only the three broad band scales were analysed.

\section{PTSD Symptoms}

Children reported on their PTSD symptoms using the Children's Responses to Trauma Inventory (CRTI; Eland \& Kleber, 1996), a self-report measure for PTSD and common other post-traumatic reactions in children, such as separation anxiety and regressive behaviour. The CRTI was developed in 1996 as the first Dutch instrument to measure children's reactions to traumatic experiences. This measure has four subscales measuring intrusion (7 items), avoidance (5 items), arousal (6 items), and non-specific symptoms (post-traumatic symptoms often displayed by children, such as regressive behaviour). The 26 items are answered on a three-point scale. The CRTI is widely used in the Netherlands for clinical and research purposes. The total score shows excellent internal consistency (alpha $=0.90)$, while internal consistency for the subscales is good (Cronbach alpha $=0.76$ for intrusion, 0.75 for arousal and 0.75 for non-specific symptoms). Only the avoidance subscale showed low internal consistency (alpha $=0.58)$. The CRTI shows adequate discriminant and convergent validity (Alisic, Eland, \& Kleber, 2006).

\section{Depressive Symptoms}

Children reported their depressive symptoms on the Child Depression Inventory (CDI; Braet \&
Timbremont, 2002; Kovacs, 1992). The widely used CDI is a 27-item self-report measure that evaluates depressive symptoms in children and adolescents. The items are answered on a three-point scale. It has good test-retest reliability and validity (Finch, Saylor, \& Edwards, 1985).

\section{Trauma-Related Cognitions}

For this study, a child version of the Post Traumatic Cognitions Inventory (PTCI; Van Emmerik, Schoorl, Emmelkamp, \& Kamphuis, 2006) was constructed to assess trauma-related cognitions. This Post Traumatic Cognitions Inventory-Child version (PTCI-C; Van Emmerik, Kamphuis, Van der Oord, Lucassen, \& Emmelkamp, 2007) had good internal consistency in the present study (alpha $=$ 0.93 ) and is answered on a three-point scale.

\section{Treatment Satisfaction}

Children and parents reported treatment satisfaction on two 4-point Likert scales ('Do you feel better after treatment?' /'Do you think your child feels better after treatment?' and 'Do you think the treatment has worked?' /'Do you think the treatment has worked for your child?').

\section{Procedures}

Children were referred to an outpatient mental health clinic for assessment and treatment of PTSD. After the intake procedure was completed and had revealed significant PTSD symptoms, parents were informed about the purpose and procedures of the study. After parents gave their informed consent, an appointment was made with the research assistant for the structured interviews with parents and children and completion of the questionnaires. After the pre-test, treatment was provided at least once every 2 weeks. Directly after the end of treatment the post-test and 6 months later the follow-up were conducted.

\section{Cognitive Behavioural Writing Therapy (CBWT)}

Treatment follows an extensive manual (Lucassen \& Van der Oord, 2008) that contains a general treatment outline and special sections for the treatment of trauma after sexual assault or the sudden death of a loved one. In addition, a special section is included on the treatment of children after trauma due to a psychiatric disorder of a parent (e.g. due to borderline personality disorder of a parent witnessing suicide attempts). 
The most important elements of the treatment are psycho-education, exposure, cognitive restructuring, promoting adequate coping and social sharing. The treatment did not include relaxation training or anxiety management techniques. The treatment manual describes age- and child-specific procedures. For younger children the therapist asks if the child is able or wants to type the story themselves on the computer. The older children type the story themselves on the computer. Among children who experienced multiple traumatic events, first, a time line of traumatic events is constructed together with the therapist. Then, together with the therapist, the child identifies the most traumatic event, which is then described in a detailed account. During the course of treatment, the written account of the traumatic event is further integrated into a complete storyline. The story begins with an introduction of the child (e.g. the name and age of the child, the family situation, short history of the life of the child, and why the child seeks treatment), than a detailed description of the traumatic event, in which the child writes down its thoughts, feelings and behavior during and after the traumatic event. Also, the cognitive distortions are written down, and after the cognitive restructuring, the more adaptive thoughts. At the end of the story the child writes how he or she feels now, and how he or she will cope in the future.

Most therapy sessions took place individually; however, joint parent-child sessions are provided when necessary (e.g. if the child displayed severe separation anxiety). The first session is devoted to psycho-education on PTSD symptoms and on the rationale of the treatment. A standard written rationale is developed for this purpose. At the end of the first session, the child formally agrees that he or she will complete the number of treatment sessions deemed appropriate by the therapist to complete the written account of the story.

During the sessions the child writes a report of the trauma on the computer in the therapy room. The therapist sits next to the child. Together with the therapist, the child first gives a title to the story (e.g. 'My story on mommy's hanging'). Next, the therapist helps the child with writing down a detailed account of the child's thoughts, feelings and behaviours during the traumatic event by asking explicit questions and giving examples about what other children who experience comparable traumatic events might think or feel (exposure). Also, during the writing of the story the therapist helps the child to restructure her or his maladaptive thoughts about him or herself, the trauma, or the world (cognitive restructuring), and learns the child how to identify and restructure his or her maladaptive thoughts. To facilitate cognitive restructuring during the CWBT, regular cognitive behavioural techniques such as Socratic questioning and verbal cognitive restructuring are used. The cognitive distortions/maladaptive thoughts are identified and written down in the story and after the cognitive restructuring the more helpful cognitions are also written down in the narrative.

In each subsequent therapy session, the child rereads the story of the trauma (exposure) and continues describing the remainder of the story. At the end of the story, the therapist and the child generate potential coping strategies for the future (e.g. 'How do I cope if I encounter my harasser?') and adequate strategies are included in the story. The child is specifically instructed to 'treasure' this detailed account of the traumatic experience, and to reread the story in case of re-occurrence of trauma symptoms. When the story is completed, the last step is 'social sharing' (Lange et al., 2003). The child and therapist discuss who are 'eligible candidates' to read the story. The story is read by important others/parents without the child being present. After this, the important others/parents, sometimes aided by the therapist, give a written and a verbal reaction to the story. The therapy ends when the therapist deems that every detail of the traumatic event is included in the written account of the story and the therapist cannot identify any maladaptive thoughts in the story. In the present sample the minimum number of sessions needed was three and the maximum number of sessions needed was 11 . The mean amount of sessions needed was $5.5(S D=2.2)$.

\section{Treatment Integrity}

Therapists were mainly psychologists, but also social workers who were trained to provide treatment. Level of experience of the therapists differed. Most therapists had several years of therapeutic experience, but also some less-experienced therapists provided treatment. Before providing the CBWT, all therapists were trained in CBWT by the second author, a therapist with 20 years of experience in treatment of children with PTSD, and the first author, a licensed cognitive-behaviour therapist. Further, all therapists received biweekly supervision by the second author (S.L.).

The training of CBWT consisted of a full-day instruction workshop, by the first and second 
author. Before participating in the workshop, each therapist was instructed to read the extensive manual (see before) and to watch the 2-hour instruction DVD. The instruction DVD consisted of multiple role-played examples (by child and therapist) of each element of the treatment (psychoeducation, exposure, cognitive-restructuring, social sharing).

After each session of the CBWT the therapist rated which element of treatment they had used in the session (psycho-education, exposure, cognitive restructuring, social sharing) and emailed the written output of each session to the senior therapist (S.L.). The senior therapist assessed adherence to the protocol by reviewing the written output of each session. The senior psychologist provided feedback on the written output of the child, and checked if important elements of treatment (psycho-education, exposure, cognitiverestructuring, social sharing) were included in the written output of the child. Further, in the biweekly supervision session, it was verified whether all important elements of treatment were carried out by the therapists.

\section{Statistical Analyses}

To assess improvement during treatment, withingroup repeated measures analyses (pre-test, posttest, follow-up) were performed on the CDI, CBCL, PTCI-C and CRTI. Effect sizes are reported for all analyses (Cohen's D; Cohen, 1988).

\section{RESULTS}

Twenty-three children were included in the study. Twenty ( $87 \%$ ) of the children, met the diagnostic criteria for PTSD, as reported on the ADIS by both the parent and child, the child only, or the parent only. Three (13\%) of the children displayed at least five PTSD symptoms, with at least one in each of the three PTSD clusters. Thirteen $(56.5 \%)$ of the children experienced traumatic complaints due to a single traumatic event, while 10 children (43.5\%) experienced PTSD symptoms due to several traumatic events. The mean age of the children was $11.87(S D=2.47) ; 6(26.1 \%)$ boys and $17(73.9 \%)$ girls participated.

Sixteen children $(69.6 \%)$ were Caucasian, while 7 children $(30.4 \%)$ were of different ethnicities (2 Turkish, $8.6 \%$; 3 North African, $12.9 \%$; and 2 South American, 8.6\%). Three (13\%), $11(47.8 \%)$ and 5 (21.6\%; 4 missing) mothers had low, moderate and high levels of education, respectively. In contrast, 7 fathers $(30.4 \%$ ) had low level of education, another 7 (30.4\%) had moderate level of education, and 3 fathers $(13 \%)$ had high level of education (6 missing).

With regard to co-morbidity, 16 children (69.6\%) had at least one additional anxiety disorder diagnosis on the ADIS (8 social phobia [34.7\%], 7 generalized anxiety disorder [30.3\%], 9 specific phobia [39.1\%] and 8 separation anxiety disorder [34.8\%]). Further, 3 children $(12.9 \%)$ had an additional diagnosis of pervasive developmental disorder, attention-deficit/hyperactivity disorder or oppositional defiant disorder, which was confirmed by a child psychiatrist. Nine $(39.1 \%)$ of the parents of the children had self-reported psychiatric problems for which they received psychiatric counselling (e.g., substance abuse or dependence, PTSD, panic disorder, borderline personality disorder or depression).

Three children (13\%) dropped out from the study. One child dropped out because during the treatment, his or her sexual assaulter was unexpectedly released from jail and the child was placed in foster care elsewhere. One child dropped out due to severe behavioural problems and placement in foster care, after his or her mother tried to shoot his or her father, was imprisoned, and attempted suicide. Finally, one child dropped out because she or he was referred to a psychiatric hospital for suicide attempts. All three children already had severe behavioural and emotional problems and unstable home situations before treatment started.

Of the final sample of 20 children completing treatment, 6 children $(30 \%)$ displayed PTSD due to the sudden death of a parent (5 children) or a brother (1 child), 1 child (5\%) experienced the sudden death of his/her mother and sudden disappearance of his/her father. One child (5\%) displayed PTSD due to the sudden disappearance of father after accusation of murder, one child (5\%) displayed PTSD due to sudden disappearance of father and an attempt of its family to violently abduct the child.

Five children $(25 \%)$ displayed PTSD symptoms due to sexual abuse, of which 3 children $(15 \%)$ were assaulted once, and $2(10 \%)$ were assaulted several times. One child (5\%) displayed PTSD after severe physical and emotional assault by peers. Further, a number of children displayed PTSD after witnessing a range of events, one child (5\%) witnessed a fatal accident, one child (5\%) witnessed his/her mother attempt suicide, one child (5\%) witnessed 
Table 1. Results of the repeated measures analyses, within-group contrasts, and effect sizes (Cohen's $d$ ) from pre-post and from post-follow-up test

\begin{tabular}{|c|c|c|c|c|c|c|c|c|}
\hline \multirow[t]{2}{*}{ Measure } & \multirow[t]{2}{*}{$\begin{array}{l}\text { Pre-test } \\
\mathrm{M}(S D)\end{array}$} & \multirow[t]{2}{*}{$\begin{array}{l}\text { Post-test } \\
\mathrm{M}(S D)\end{array}$} & \multirow[t]{2}{*}{$\begin{array}{l}\text { Follow-up } \\
\mathrm{M}(S D)\end{array}$} & \multirow[t]{2}{*}{$F(d f)$ Time } & \multicolumn{2}{|c|}{ Pre-Post test } & \multicolumn{2}{|c|}{$\begin{array}{l}\text { Post-Follow- } \\
\text { up test }\end{array}$} \\
\hline & & & & & $F(d f)$ & $d$ & $F(d f)$ & $d$ \\
\hline CTRI & $48.76(9.33)$ & $32.33(9.83)$ & $30.67(6.20)$ & $21.18(16)^{* *}$ & $27.69(1)^{* *}$ & 1.71 & $0.60(1)$ & 0.20 \\
\hline Intrusion & $14.00(3.56)$ & $8.72(2.56)$ & $8.39(2.43)$ & $18.75(16)^{* *}$ & $33.61(1)^{* *}$ & 1.70 & $0.26(1)$ & 0.13 \\
\hline Avoidance & $11.26(2.27)$ & $7.61(2.68)$ & 7.28 (1.56) & $20.52(16)^{* *}$ & $17.82(1)^{* *}$ & 1.47 & $0.32(1)$ & 0.15 \\
\hline Arousal & $9.89(2.97)$ & $6.17(2.33)$ & $6.00(1.75)$ & $11.65(16)^{* *}$ & $22.60(1)^{* *}$ & 1.39 & $0.11(1)$ & 0.08 \\
\hline Non-specific & $13.61(2.52)$ & $9.83(3.20)$ & 9.00 (1.24) & $19.88(16)^{* *}$ & $16.73(1)^{* *}$ & 1.31 & $1.2(1)$ & 0.34 \\
\hline PTCI-C & 16.00 (10.77) & 8.47 (10.83) & $5.54(4.98)$ & $9.01(15)^{* *}$ & $13.89(1)^{* *}$ & 0.70 & $1.36(1)$ & 0.35 \\
\hline CDI & $9.74(6.23)$ & $5.41(5.30)$ & $3.06(4.27)$ & $9.42(16)^{* *}$ & $9.47(1)^{* *}$ & 0.75 & $2.13(1)$ & 0.49 \\
\hline CBCL-total & $60.35(6.84)$ & $51.53(8.02)$ & $48.71(6.88)$ & $18.94(15)^{* *}$ & $13.94(1)^{* *}$ & 1.18 & $1.75(1)$ & 0.38 \\
\hline CBCL- int & 64.53 (7.39) & $52.76(11.49)$ & $48.42(7.91)$ & $32.98(15)^{* *}$ & $17.47(1)^{* *}$ & 1.22 & $3.48(1)^{1}$ & 0.44 \\
\hline CBCL- ext & $55.65(7.94)$ & $50.29(8.93)$ & $49.53(6.18)$ & $5.72(15)^{*}$ & $5.95(1)^{*}$ & 0.63 & $0.14(1)$ & 0.10 \\
\hline
\end{tabular}

${ }^{*} p<0.05,{ }^{* *} p<0.01$.

Note: CTRI $=$ Child Traumatic Reactions Index. PTCI-C $=$ Post Traumatic Cognitions Inventory-Child version. CDI $=$ Child Depression Inventory. CBCL total $=$ Child Behavior Check List total score. CBCL-int $=$ Child Behavior Check List internalizing. CBCL-ext $=$ Child Behavior Check List externalizing.

${ }^{1}$ Trend, $p=0.08$

severe assault of its father, and two children (10\%) witnessed severe and long-term domestic violence, in which they were also emotionally abused.

The mean time since the most recent traumatic experience was 33.24 months $(S D=37.70$; range $1-108)$. The mean duration of PTSD symptoms was 27.44 months $(S D=34.77$; range 1-96).

Two children completed treatment but were lost to follow-up, resulting in a final total sample of 18 children with pre-test-post-test-follow-up data. Table 1 displays means and SDs at pre-test, posttest, and 6 months follow-up for the completers, results from the repeated measures analyses, effect sizes for each outcome measure, and the within group contrasts from pre- to post-test and post- to follow-up test.

There was a significant main effect for all outcome measures, and post-hoc contrasts showed that for all outcomes measures there was a significant improvement from pre- to post-test and a non-significant effect from post- to follow-up test. Additionally, an intent-to-treat analysis was conducted on all 23 participating children, in which missing item responses of the dropouts were predicted using SPSS missing value analysis based on regression models (Roth, Switser, \& Switser, 1999). Results were similar to the completers analysis: there was a significant main effect for all outcome measures, with significant improvement from preto post-test, and non-significant effects from post- to follow-up test. Only the CBCL internalizing-scale now showed a significant reduction from post-test to follow-up (data available from first author).

For the completers, satisfaction ratings showed that $75 \%$ of the children reported to feel very much better at post-test and 20\% reported to feel a lot better (5\% missing). Also, $60 \%$ of the parents reported that their child felt very much better, $25 \%$ reported that their child felt a little better, and $5 \%$ reported that their child felt the same $(10 \%$ missing).

Further, $60 \%$ of the children reported that the writing therapy helped them very much, $25 \%$ a lot, and $10 \%$ a little (5\% missing). Finally, 35\% of the parents of the children reported that the writing therapy helped their child very much, $40 \%$ a lot and $10 \%$ a little (15\% missing).

\section{DISCUSSION}

This study evaluated the potential effectiveness of a brief, computed-aided, cognitive behavioural writing therapy for children with PTSD. The study shows promising results: with a mean of only 5.5 sessions the children displayed a significant decrease of their PTSD and depressive symptoms, and internalizing and externalizing behavioural problems, and this effect was maintained at 6 months follow-up. Of note, the effect size on the PTSD outcome measure was very large. The present results are comparable or even slightly 
better compared to most other studies on TF-CBT in children (e.g. Deblinger et al., 1996; King et al., 2000).

This study was conducted in an outpatient community mental health setting in the Netherlands. The children participating in the study had experienced different single or recurring traumatic experiences, and often had a non-Caucasian ethnic background $(30 \%)$ or a parent with a psychiatric diagnosis $(39.1 \%)$. Therefore, the present sample seems to be representative of the variety of children and traumatic experiences encountered in clinical practice, and the results of this study are highly generalizable to clinical practice. Also, the treatment proved feasible in this clinical community setting. Future research is needed to know which of these variables (e.g. ethnicity, psychiatric diagnosis of parents) are related to treatment outcomes.

\section{Limitations}

In the absence of a control condition, we cannot ascertain that the observed improvements can be attributed to the specific treatment procedures, instead of non-specific treatment factors, such as contact with the services, repeated assessments or maturation effects. Given that most children already had clinically significant symptoms for a long period of time before treatment started (mean duration of symptoms was 27.44 months) and $43.5 \%$ of the children had experienced multiple traumatic events, it is unlikely that the present substantial improvements in such a short time period can be accounted for by spontaneous recovery. This is further supported by the satisfaction ratings of both the children and their parents. Given the encouraging results, there is a clear need of a controlled study in which writing therapy is compared with conventional CBT and no-treatment control.

Further, some of the measures were specifically constructed for this study (i.e. the PTCI-C, the treatment satisfaction) and the subscale of the CTRI 'avoidance' showed low internal consistency; thus, the results should be interpreted cautiously. Future studies should therefore further validate these measures.

\section{Strengths}

CBWT has a number of advantages over conventionalCBT in children. First, it consists of procedures that are appealing and motivating to children, i.e. the computer to construct a written account of the traumatic event. Some authors suggest that the use of a computer or typing to complete written exposure exercises allows avoidance of trauma-related material through emotional disengagement and is less effective then written or spoken exposure (Brewin \& Lennard, 1999). However, a meta-analysis in adults shows no difference in mode of disclosure (handwriting, speaking or typing) on outcome (Frattaroli, 2006). Also, the effect sizes we report are comparable, or even slightly better than effect sizes reported in other studies using conventional exposure (Deblinger et al., 1996; King et al., 2000). More research is needed into the specific role (e.g. more motivating or emotionally (dis)engaging) of using the computer to aid exposure in children and adolescents. It can also be argued that especially for children and adolescents, of who the computer is more a part of their daily lives and communication than adults, the use of the computer enhances emotional engagement.

Second, by creating a storyline of the traumatic event during the whole course of the treatment and by also writing down the more adaptive thoughts that are a result of cognitive restructuring, the exposure and restructuring can be reread every session and for years on. Also, this written document can be shared with significant others. Explicitly integrating the whole treatment and all its elements (exposure, cognitive restructuring, social sharing) into one storyline and document may be beneficial for treatment outcome. It may improve insight and increase understanding of causal factors of a particular traumatic event (e.g. Frattoli, 2006), not only for the child but also for the person with whom the story is shared. In conventional CBT for children, creating a written document of the traumatic event is often part of the therapy, but never used solely (Cohen et al., 2006). It is always used next to other treatment modules, such as relaxation, affect modulation and cognitive coping (Cohen et al., 2006).

Especially for children and adolescents, the use of a storyline during the whole course of the therapy may be more appealing than for adults. By connecting to the way of how children express themselves (through a chronological storyline), processing of the traumatic event and engagement to therapy is possibly easier. The use of the storyline facilitates the child to make a coherent story of the traumatic event with a beginning and an end, and, thus, may facilitate processing of the traumatic event and adherence/engagement to treatment (i.e. only end the treatment when the story is finished). Also, perhaps other subgroups of adults (e.g. those with 
lower IQs or more cognitive avoidance), with whom regular CBT is often difficult, may benefit from CWBT. However, more research is needed into the developmental specific mechanisms of the use of a storyline in treatment of PTSD and the application of CWBT in subgroups of adults.

Third, the treatment length is relatively short compared to other treatment manuals. Prior studies report treatment lengths from 10 (Smith et al., 2007) to 18 sessions (March, Amaya-Jackson, Murray, \& Schulte, 1998), while the current treatment needed only a mean of five sessions. This is possibly due to the focus of the treatment on the most important elements of treatment (exposure, cognitive-restructuring and social sharing), while other non-effective elements (such as relaxation techniques, or affect modulation; Bisson et al., 2007) often included in other trauma-focused CBT manuals (e.g. Cohen et al., 2004, 2006; King et al., 2000) are not included in the treatment. Additionally, despite the mean amount of only five sessions, treatment results are maintained at 6 months follow-up. Finally, mental health professionals can easily be trained and supervised in this treatment. Writing assignments easily lend themselves for detailed feedback (e.g. by e-mail). In summary, this is the first study into the potential effectiveness of brief, computer-aided CBWT for children and adolescents with PTSD, exposed to a wide range of traumatic events, in a highly representative clinical sample and community setting. Despite the open label nature of the study, it shows encouraging and promising results, that underline the importance of evaluation of this treatment in a randomized controlled trial.

\section{REFERENCES}

Achenbach, T.M. (1991). Manual for the Child Behavior Check List. Burlington: University of Vermont, Department of Psychiatry.

Alisic, E. Eland, J., \& Kleber, R.J. (2006). The Children's Responses to Trauma Inventory (CRTI): Development, validation, and preliminary normative data. Utrecht, The Netherlands: Institute for Psychotrauma.

Bichescu, D., Neuner, F., Schauer, M., \& Elbert, T. (2007). Narrative exposure therapy for political imprisonment-related chronic posttraumatic stress disorder and depression. Behaviour Research and Therapy, 45, 2212-2220.

Bisson, J.I., Ehlers, A., Matthews, R., Pilling, S., Richards, D., \& Turner, S. (2007). Psychological treatments for chronic post-traumatic stress disorder. Systematic review and meta-analysis. British Journal of Psychiatry, 190, 97-104.
Bolton, D., O'Ryan, D., Udwin, O., Boyle, S., \& Yule, W. (2000). The long-term psychological effects of a disaster experienced in adolescence. Journal of Child Psychology and Psychiatry, 41, 513-523.

Braet, C., \& Timbremont, B. (2002). Children's Depression Inventory-Dutch version. Amsterdam: Harcourt test Publishers.

Brewin, C.R., Andrews, B., \& Valentine, J.D. (2000). Meta-analysis of risk factors for posttraumatic stress disorder in trauma-exposed adults. Journal of Consulting and Clinical Psychology, 68, 748-766.

Brewin, C.R., \& Lennard, H. (1999). Effects of modes of writing on emotional narratives. Journal of Traumatic Stress, 12, 355-361.

Cohen, J. (1988). Statistical power analysis for the behavioral sciences (2nd ed.). New York: Academic Press.

Cohen, J.A., Deblinger, E., Mannarino, A.P., \& Steer, R.A. (2004). A multisite randomized controlled trial for children with sexual abuse-related PTSD symptoms. Journal of the American Academy of Child and Adolescent Psychiatry, 43, 393-402.

Cohen, J.A., Mannarino, A.P., \& Deblinger, E. (2006). Treating trauma and traumatic grief in children and adolescents. New York: Guilford Press.

Cohen, J.A., Mannarino, A.P., \& Staron, V.R. (2006). A pilot study of modified cognitive-behavioral therapy for childhood traumatic grief (CBT-CTG). Journal of the American Academy of Child and Adolescent Psychiatry, 45, 1465-1473.

Cuffe, S.P., Addy, C., Garrison, C.Z., Waller, J.L., Jackson, K.L., McKeown, R.E., \& Chilappagari, S. (1998). Prevalence of PTSD in a community sample of older adolescents. Journal of the American Academy of Child and Adolescent Psychiatry, 37, 147-154.

Deblinger, E., Lippman, J., \& Steer, R. (1996). Sexually abused children suffering posttraumatic stress symptoms: Initial treatment outcome findings. Child Maltreatment, 1, 310-321.

Ehlers, A., \& Clark, D.M. (2000). A cognitive model of posttraumatic stress disorder. Behaviour Research and Therapy, 38, 319-345.

Eland, J., \& Kleber, R.J. (1996). Schokverwerkingslijst voor (jonge) kinderen [Children's Responses to Trauma Inventory]. Utrecht, The Netherlands: Institute voor Psychotrauma.

Finch, A.J., Saylor, C.F., \& Edwards, G.L. (1985). Children's Depression Inventory: sex and grade norms for normal children. Journal of Consulting and Clinical Psychology, 53, 424-425.

Finkelor, D., Turner, H., \& Ormrod, R. (2006). Kid's stuff: the nature and impact of peer and sibling violence on younger and older children. Child Abuse E Neglect, 30, 1401-1421.

Frattaroli, J. (2006). Experimental disclosure and its moderators: a meta-analysis. Psychological Bulletin, 132, 823-865.

Giaconia, R.M., Reinherz, H.Z., Silverman, A.B., Pakiz B., Frost, A.K., \& Cohen, E. (1995). Traumas and posttraumatic stress disorder in a community population of older adolescents. Journal of the American Academy of Child and Adolescent Psychiatry, 34, 13691380. 
King, N.J., Tonge, B.J., Mullen, P., Myerson, N., Heyne, D., Rollings, S., Martin, R., \& Ollendick, T.H. (2000). Treating sexually abused children with posttraumatic stress symptoms: A randomized clinical trail. Journal of the American Academy of Child and Adolescent Psychiatry, 39, 1347-1355.

Kovacs, M. (1992). Children's Depression Inventory Manual. North Tonawanda, NY: Multi-Health Systems.

Lange, A., Rietdijk, D., Hudcovicova, M., Van de Ven, J-P., Schrieken, S., \& Emmelkamp, P.M.G. (2003). INTERAPY. A controlled randomized trial of the standardized treatment of posttraumatic stress through the Internet. Journal of Consulting \& Clinical Psychology, 71, 901-909.

Lucassen, S., \& Van der Oord, S. (2008). WRITEjr; protocol schrijftherapie voor getraumatiseerde kinderen en adolescenten [WRITEjr; manual for writing therapy for traumatized children and adolescents]. Amsterdam: Uitgeverij SWP.

March, J.S., Amaya-Jackson, L., Murray, M.C., \& Schulte, A. (1998). Cognitive-behavioral psychotherapy for children and adolescents with posttraumatic stress disorder after a single-incident stressor. Journal of the American Academy of Child and Adolescent Psychiatry, 37, 585-593.

Neuner, F., Schauer, M., Klaschik, C., Karunakara, U., \& Elbert, T. (2004). A comparison of Narrative Exposure Therapy, supportive counseling, and psychoeducation for treating Post Traumatic Stress Disorder in an African refugee settlement. Journal of Consulting and Clinical Psychology, 72, 579-587.

Neuner, F., Catani, C., Ruf, M., Schauer, E., Schauer, M., \& Elbert, T. (2008). Narrative exposure therapy for the treatment of traumatized children and adolescents (KidNET): From neurocognitive theory to field intervention. Child Adolescent Psychiatric Clinic North America, 17, 641-664.

Ozer, E.J., \& Weinstein, R.S. (2004). Urban adolescents' exposure to community violence: the role of support, school safety, and social constraints in a school-based sample of boys and girls. Journal of Clinical Child and Adolescent Psychiatry, 33, 463-476.

Onyut, L.P., Neuner, F., Schauer, E., Ertl, V., Odenwald, M., Schauer, M., \& Elbert, T. (2005). Narrative Exposure Therapy as a treatment for child war survivors with posttraumatic stress disorder: Two case reports and a pilot study in an African refugee settlement, BMC Psychiatry, 5, 1-9.

Roth, P.L., Switzer, F.F., \& Switzer, D.M. (1999). Missing data in multiple item scales: A Monte Carlo analysis of missing data techniques. Organizational Research Methods, 2, 211-232.

Schauer, E., Neuner, F., Elbert, T., Ertl, V., Onyut, L.P., Odenwald, M., \& Schauer, M. (2004). Narrative exposure therapy in children: A case study. Intervention, 2, 18-38.

Siebelink, B.M., \& Treffers, Ph.D.A. (2001). Dutch translation of Anxiety Disorder Interview Schedule for DSM-IV Child Version. Lisse/Amsterdam: Swets \& Zeitlinger.

Silverman, W.K., \& Albano, A.M. (1996). Anxiety Disorders Interview Schedule for DSM-IV Child Version, Child Interview Schedule. San Antonio: The Psychological Corporation.

Silverman, W.K., Ortiz, C.D., Viswesvaran, C., Burns, B.J., Kolko, D.J., Putman, F.W., \& Amaya-Jackson, L. (2008). Evidence-based psychosocial treatments for children and adolescents exposed to traumatic events. Journal of Clinical Child and Adolescents, 37, 156183.

Sloan, D.M, Marx, B.P., \& Epstein, E.M. (2005). Further examination of the exposure model underlying the efficacy of written emotional disclosure. Journal of Consulting and Clinical Psychology, 73, 549-554.

Sloan, D.M., Marx, B.P., Epstein, E.M., \& Lexington, J.M. (2007). Does altering the writing instructions influence outcome associated with written disclosure? Behavior Therapy, 38, 155-168.

Smith, P., Yule, W., Perrin, S., Tranah, T., Dalgleish, T., \& Clark, D. (2007). A randomized controlled trial of individual cognitive behavior therapy for PTSD in children and adolescents. Journal of the American Academy of Child and Adolescent Psychiatry, 46, 1051-1061.

Stein, B.D., Jaycox, L.H., Kataoka, S.H., Wong, M., Tu, W., Elliot, M.N., \& Fink, A. (2003). A mental health intervention for schoolchildren exposed to violence: a randomized controlled trial. Journal of the American Medical Association, 290, 603-611.

Van Emmerik, A.A.P., Kamphuis, J.H., \& Emmelkamp, P.M.G. (2008). Treatment of acute stress disorder and posttraumatic stress disorder with cognitive behavioral therapy or structured writing therapy: A randomized controlled trial. Psychotherapy \& Psychosomatics, 77, 93-100.

Van Emmerik, A.A.P., Schoorl, M., Emmelkamp, P.M.G., \& Kamphuis, J.H. (2006). Psychometric evaluation of the Dutch version of the posttraumatic cognitions inventory (PTCI). Behaviour Research and Therapy, 44, 1053-1065.

Van Emmerik, Kamphuis, J.H., Van der Oord, S., Lucassen, S., \& Emmelkamp, P.M.G. (2007). A Dutch version of the Posttraumatic Cognitions Inventory- Child version (PTCI-C). In preparation.

Yule, W., Bolton, D., Udwin, O., Boyle, S., O'Ryan, D., \& Nurrish, J. (2000). The long-term psychological effects of a disaster experienced in adolescence: I: The incidence and course of PTSD. Journal of Child Psychology and Psychiatry and Allied Disciplines, 41, 503-511. 